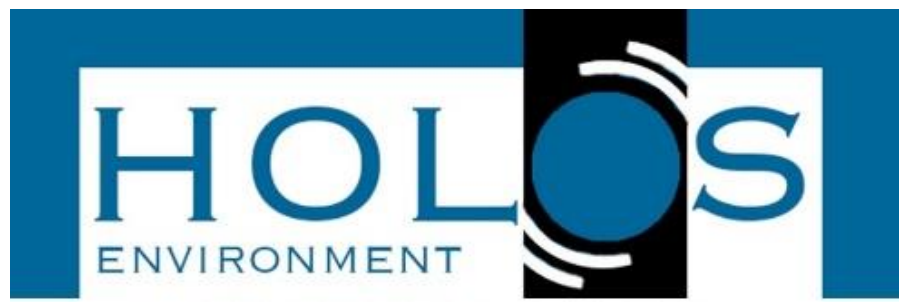

\title{
BARRAGEM DO RIO TODOS OS SANTOS NO VALE DO MUCURI/MG: ANÁLISE DE ROMPIMENTO PARA TEÓFILO OTONI
}

\section{DAMAGE OF THE RIO ALL THE SAINTS IN THE VALLEY OF MUCURI/MG: ANALYSIS OF BREAKDOWN FOR TEÓFILO OTONI}

\author{
Alexandre Sylvio Vieira da Costa ${ }^{1}$; Altamiro Junior Mendes Silva ${ }^{1}$; \\ Rodrigo Silva Colares ${ }^{1}$
}

Artigo recebido em: 28/05/2019 e aceito para publicação em: 21/11/2019. DOI: http://dx.doi.org/10.14295/holos.v19i4.12344

\begin{abstract}
Resumo: Grandes obras da engenharia são projetadas para solucionar ou minimizar problemas. Neste trabalho é apresentado um estudo sobre a barragem que visa abastecer e satisfazer as necessidades da região, mas que podem gerar alguns transtornos caso o barramento se rompa. Desta forma a pesquisa avaliou as ondas de inundação provenientes do rompimento hipotético da barragem de Teófilo Otoni-MG. Para a realização deste estudo foi utilizado o método das características descrito por Mascarenhas. A vazão máxima de ruptura calculada resultou no valor de $5739,34 \mathrm{~m}^{3} / \mathrm{s}$, utilizando o hidrograma triangular simplificado de ruptura. O tempo estimado de esvaziamento do reservatório é de aproximadamente 4.460,44 segundos (1,24 horas). Com base nos dados encontrados, percebemos que a sede municipal de Teófilo Otoni, situada a $15 \mathrm{~km}$ da barragem, seria atingida por um fenômeno de galgamento, cuja altura seria de aproximadamente três metros. Observa-se, neste desfecho, que os resultados obtidos no desenvolvimento dessa proposta de estudo, podem ampliar as possibilidades de ações relativas à prevenção de catástrofes, no que tange à construção, manutenção e rompimento involuntário de uma barragem de contenção, e incentivar estratégias emergenciais de apoio, em caso de situações de risco iminente.
\end{abstract}

Palavras-chave: Rompimento. Barragem. Rio Todos os Santos. Alagamento.

\begin{abstract}
Major engineering works aredesigned to solve or minimize problems. This work presents a study on the dam that aims to supply and satisfy the needs of the region, but which can generate some inconvenience if the bus breaks. In this way, the research evaluated the flood waves from the hypothetical rupture of the Teófilo Otoni-MG dam. For the accomplishment of this study was used the method of the characteristics described by Mascarenhas. The calculated maximum rupture rate was 5739.34 $\mathrm{m}^{3} / \mathrm{s}$, using the simplified triangular rupture hydrograph. The estimated time of emptying the reservoir is approximately $4,460.44$ seconds ( 1.24 hours). On thebasis of the data found, we noticed that the municipal seat of Teófilo Otoni, located $15 \mathrm{~km}$ from the dam, would be hit by a fencing phenomenon, whose height would be approximately 3 meters. It is observed in this conclusion that the results obtained in the development of this study proposal can increase the possibilities of actions related to the prevention of catastrophes, with respect to the construction, maintenance and involuntary rupture of a barrage of containment, and to encourage emergency strategies support, in case of imminent risk situations.
\end{abstract}

Keywords: Breaking. Dam. River Todos os Santos. Flood.

\footnotetext{
${ }^{1}$ Universidade Federal dos Vales do Jequitinhonha e Mucuri (UFVJM), Teófilo Otoni, MG. E-mails: (asylvio@hotmail.com, altamiro.silva@ufvim.edu.br, rodrigo.colares@ufvim.edu.br)
} 


\section{INTRODUÇÃO}

\subsection{Histórico do Rio Todos os Santos}

Em 08 de março de 1730 surgiram as primeiras informações sobre o curso do rio Todos os Santos. Anteriormente, a bacia do rio São Mateus, ainda era desconhecida pela maioria da população de Minas Gerais. Durante as incursões na região descobriu-se o Vale do Mucuri e, o Rio Todos os Santos. Com a construção da Estrada de Ferro Bahia/Minas (EFBM), por volta de 1882, o então navegável Rio Todos os Santos contribuiu para a colonização do Vale do Mucuri. A EFBM acompanha seu leito por, aproximadamente, $100 \mathrm{~km}$, desde o Distrito de Valão, município de Poté, até a sua foz no distrito de Presidente Pena, município de Carlos Chagas.

Os principais problemas dos recursos hídricos do rio Todos os Santos estão relacionados com a contaminação e degradação de suas águas, consequência da falta de tratamento dos esgotos domésticos, industriais e atividades humanas. No ano de 2003 lançou-se, na cidade de Teófilo Otoni, um projeto de revitalização do rio Todos os Santos, onde as Secretarias de Meio Ambiente e da Educação, promoveram um trabalho abordando dos benefícios de preservação do rio.

\subsection{Aspectos pluviográficos}

Entre as diversas fases básicas do ciclo hidrológico, considera-se que a mais importante para a engenharia seja a do escoamento superficial, cuja fase aborda a ocorrência e transporte da água na superfície terrestre, isso porque a maioria dos estudos hidrológicos está ligada ao aproveitamento da água superficial e à proteção contra os fenômenos provocados pelo seu deslocamento. O escoamento superficial compreende desde o excesso de precipitação, que ocorre logo após uma chuva intensa e se desloca aleatoriamente pela superfície do terreno, até o escoamento de um rio, que pode ser alimentado tanto pelo excesso de precipitação como pelas águas subterrâneas.

Dentre os fatores de natureza climática que influem no escoamento superficial, destaca-se a precipitação antecedente, que ocorre quando o solo está úmido devido a uma chuva anterior e apresenta maior facilidade de escoamento. Outro fator climático importante é a duração e intensidade da chuva, pois quanto maior a intensidade, 
mais rápido o solo atinge a sua capacidade máxima de infiltração promovendo um excesso de água que escoará superficialmente. A duração também é diretamente proporcional ao escoamento, pois para chuvas de intensidade constante, haverá maior oportunidade de escoamento quanto maior for a duração. Quanto aos fatores fisiográficos os mais significantes são a área, a forma, a permeabilidade, associada à capacidade de infiltração, e a topografia da bacia. A interferência da área e forma do território são de fácil percepção, pois sua dimensão está relacionada à maior ou menor quantidade de água que ela pode captar. A permeabilidade do solo está diretamente ligada à capacidade de infiltração, pois quanto mais permeável for o solo, maior será a quantidade de água que ele pode absorver, diminuindo assim a ocorrência de excesso de precipitação.

Estes e outros fatores são essenciais em um projeto de construção de barragem como, por exemplo as obras hidráulicas, que acumulando água em um reservatório, reduzem as vazões máximas do escoamento superficial e retardam a sua propagação. Dentre as grandezas que caracterizam um escoamento superficial merecem destaque: vazão, tempo de concentração, nível de água, entre outros. De forma básica, a vazão, ou volume escoado por unidade de tempo, é a principal grandeza que caracteriza um escoamento. O tempo de concentração mede o tempo gasto para que toda a bacia contribua para o escoamento superficial na seção considerada. Assim, o nível da água é uma das grandezas mais imediatas de serem medidas em um curso d'água. É expressa em metros e se refere à altura atingida pelo nível d'água em relação a um nível de referência. Geralmente, as palavras "cheia" e "inundação" estão relacionadas ao nível d'água atingido, onde "cheia" refere-se a uma elevação normal do curso d'água dentro do seu leito, e inundação à elevação não usual do nível, provocando transbordamento e possíveis prejuízos. Quando se faz referência a dados pluviográficos, estes são ainda escassos em certas cidades brasileiras e, mesmo em regiões onde a densidade de postos pluviográficos é satisfatória, o tratamento sistemático dos registros disponíveis nem sempre permite sua pronta utilização em projetos. Assim, estes dados nem sempre estão disponíveis na região de interesse, ou o tratamento sistemático dos registros, quando disponíveis, nem sempre permite sua pronta utilização nos diversos projetos. Tendo em vista a importância do conhecimento das chuvas de curta duração e alta intensidade, especificamente nos estudos de drenagem urbana em geral, e mesmo no controle da erosão, existe a necessidade de se analisar e processar os dados pluviográficos. A manutenção 
de arquivos de dados coletados e atualizados de forma permanente, devido, principalmente, ao caráter instável da ocorrência das chuvas é de fundamental importância. Logo, percebe-se que a sistematização dos dados de chuva para uma determinada região facilita, consideravelmente, a atuação dos profissionais da área que, frequentemente, trabalham no dimensionamento de projetos, construção e operação de portos, barragens, entre outros exemplos de obras da engenharia civil.

A cidade de Teófilo Otoni, localizada no nordeste do Estado de Minas Gerais, apresentava graves problemas de abastecimento de água em períodos de estiagem. Para solucionar este problema, a COPASA juntamente com a Prefeitura Municipal e o Governo de Minas Gerais construíram uma barragem localizada a $15 \mathrm{~km}$ da sede municipal com o objetivo de garantir o abastecimento de água para toda sua população, além de reduzir os transtornos causados pelas enchentes e inundações no período de elevadas precipitações. Entretanto, caso ocorra o rompimento da barragem, os danos causados e a área que seria afetada pelo volume de água não estão definidos. O mapeamento de áreas inundáveis relacionados a um possível rompimento de barragem é uma ferramenta de grande importância na elaboração de planos de ações emergenciais, pois os danos causados pela sua ruptura, poderia apresentar consequências trágicas. Em alguns países exige-se, sob forma de lei, que os projetos de construção de barragens de médio e grande porte contenham o estudo visando elaboração de planos emergenciais. No Brasil, as empresas responsáveis pela construção de barragens realizam estes estudos, considerando a Lei 12.334 publicada no Diário Oficial da União de 21 de setembro de 2010 que estabelece a Política Nacional de Segurança de Barragens destinadas à acumulação de água para quaisquer usos, à disposição final ou temporária de rejeitos e à acumulação de resíduos industriais. Esta mesma lei cria o Sistema Nacional de Informações sobre Segurança de Barragens e altera a redação do artigo 35 da Lei 9.433, de 8 de janeiro de 1997, e do artigo 4 da Lei 9.984, de 17 de julho de 2000. Porém, no caso da barragem de Teófilo Otoni, não há registro de estudos para mostrar os efeitos causados pelo rompimento da mesma.

O possível rompimento de uma barragem é uma potencial fonte de risco para a população, fauna e flora das áreas adjacentes à mesma, bem como para o aproveitamento hídrico do vale à jusante (COLUCCI, 2011). Avaliações de escoamento superficial no campo são de custo elevado e de longos períodos de avaliação. Isto tem estimulado o desenvolvimento e utilização de modelos matemáticos para predizer o 
escoamento superficial (MA et al., 1998). Dentre os métodos para estimar as vazões máximas de escoamento superficial, destacam-se: o método racional, o método de Cook, o Hidrograma Unitário e a fórmula de Mac Math. Dentre os métodos para calcular o volume total escoado superficialmente, destacam-se o do Balanço Hídrico Diário e o Método do Número da Curva, e para ambos os métodos, são requeridos o conhecimento da chuva de projeto e o da capacidade de infiltração da água no solo (PRUSKI et al., 1997). Para a simulação do escoamento originado pela ruptura de barragens, é possível aplicar diferentes modelos numéricos, ressaltando, no entanto, que os resultados gerados pela utilização de modelos numéricos são influenciados, principalmente pelo método numérico utilizado; pelas condições iniciais e de contorno assumidas; e pela quantidade de dados de entrada utilizados (RAMOS e VISEU, 1999).

Segundo Palmier (2007), modelos hidrodinâmicos unidimensionais são os indicados para a maioria dos casos práticos, pois possuem uma interface mais simples de utilização e apresentam uma boa precisão de resultados. Para qualquer análise de ruptura de barragens, tornase necessária a elaboração de um hidrograma da vazão no momento da ruptura, destacando-se principalmente, a forma da brecha e o tempo de formação da mesma (BRASIL et al, 2006). Outro ponto que não pode ser desconsiderado é a determinação do pico de efluente, devido à ruptura (Brasil et al, 2005). Diversas equações matemáticas são estabelecidas com o objetivo de relacionar a máxima vazão de descarga com características da barragem. Palmier (2007) mostra que as diferentes abordagens existentes na determinação das vazões de pico e do hidrograma de ruptura podem afetar a taxa de escoamento da água e o potencial de inundação das áreas a jusante. Assim, analisamos que para cada barragem podem ser construídos diversos cenários de ruptura. Um aspecto importante é a determinação da vazão máxima de descarga decorrente à ruptura. A equação de Lou (1981) foi desenvolvida a partir da análise de dezenove diferentes casos de ruptura de natureza diversa.

Qmáx=7,683. $H^{1,909}$ (equação de Lou)

Onde $Q$ é a descarga máxima defluente da barragem em ruptura em $\mathrm{m} 3 / \mathrm{s}$ e H é a altura da barragem em metros. Pelo hidrograma triangular simplificado 
(MASCARENHAS, 1990), o tempo de esvaziamento do volume de água armazenado no reservatório pode ser encontrado pela relação:

$$
t_{e}=\frac{2 V}{Q_{m a ́ x}}
$$

Em que te é o tempo de esvaziamento em horas, $V$ é o volume de água armazenado no reservatório em $m^{3}$ e $Q m a ́ x$ é a vazão máxima em $m^{3} / h$.

A barragem construída na cidade de Teófilo Otoni abastece uma população de 141.046 mil habitantes. Em sua capacidade máxima, seu volume atinge $12,8 \times 10^{6}$ $\mathrm{m}^{3}$ de água. A realização destes modelos de análise subsidia órgãos governamentais, como os bombeiros, defesa civil, polícia, entre outros, para que ações sejam programadas para que o possível rompimento de uma barragem minimize os danos a população.

Esta pesquisa teve como principal objetivo identificar os impactos ambientais, bem como a área inundada e a população atingida, causados em decorrência do possível rompimento da Barragem localizada no município de Teófilo Otoni/MG.

\section{MATERIAL E MÉTODOS}

O Rio Todos os Santos tem sua origem no Município de Poté, numa localidade denominada Barrinha de Todos os Santos, onde estão localizadas mais de 40 nascentes que o formam. O Rio Todos os Santos, a partir desse ponto, percorre mais de 172 km, cortando os municípios de Poté, Teófilo Otoni e Carlos Chagas onde deságua no Rio Mucuri. Sua vazão média é de aproximadamente 700 L/s e Q7,10 de 290L/s. Dessa vazão, a COPASA retira $360 \mathrm{~L} / \mathrm{s}$ para abastecer a cidade de Teófilo Otoni. Porém, durante os períodos de estiagem a vazão desse manancial cai significativamente. Há registros de que no final de 1998 e início de 1999, o volume de água do rio Todos os Santos reduziu para vazões próximas de $200 \mathrm{l} / \mathrm{s}$. Como consequência, neste período, a cidade teve o fornecimento de água potável racionado. A construção da barragem teve como objetivo reforçar o abastecimento de água na cidade de Teófilo Otoni e controlar a vazão do Rio Todos os Santos. Para a implantação da barragem, as áreas vertentes ao reservatório, um total de 17 propriedades, foram desapropriadas pela COPASA, formando uma área de preservação ambiental composta por 
aproximadamente 1.000 hectares, dos quais 130 hectares são correspondentes ao espelho d'água, como pode ser observado na Figura 1.

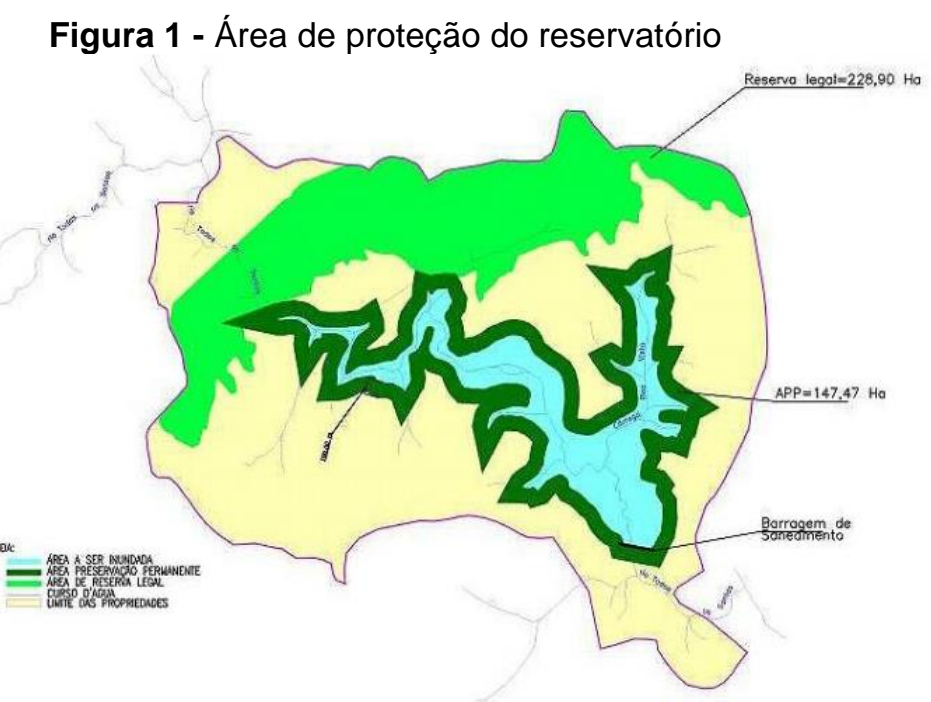

Fonte: COPASA

A barragem do Rio Todos os Santos (Figura 2) é constituída de uma estrutura tipo solo compacto, com uma área inundada total de 128,4 ha, contando com uma bacia hidrográfica contribuinte de $158,8 \mathrm{~km}^{2}$.

Figura 2 - Vistas da jusante e montante da barragem do rio Todos os Santos

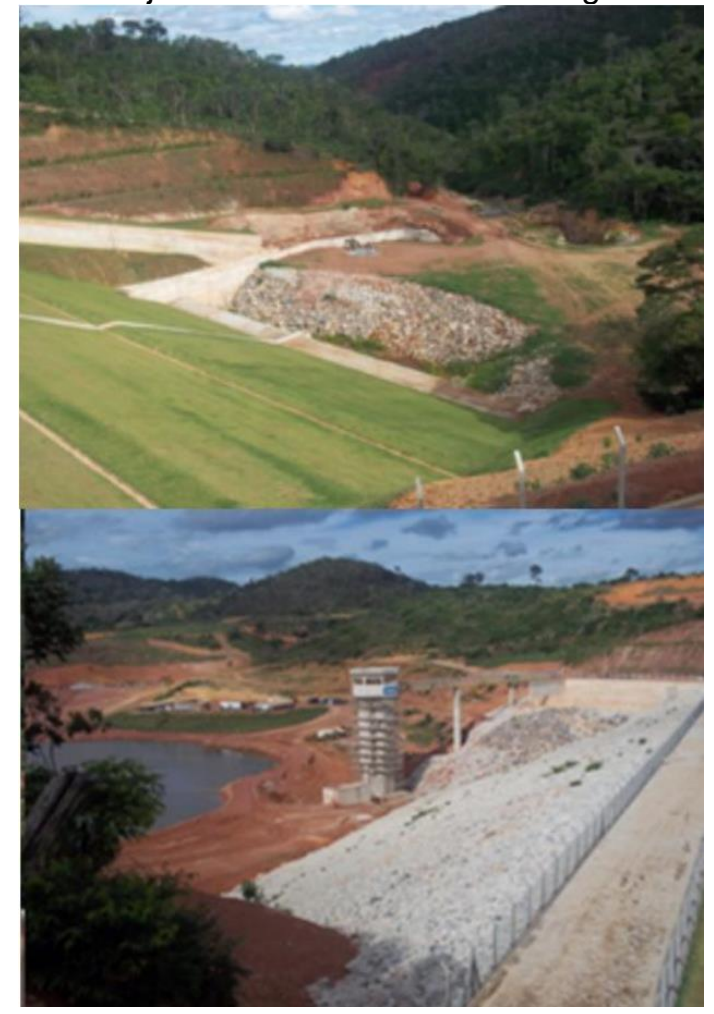


A altura máxima da barragem é de 32,0 m e a sua crista possui um comprimento total de 180,0 m. O volume total (N.A. máximo normal) é de $12,8 \times 10^{6} \mathrm{~m}^{3}$ e a vazão regularizada é $0,548 \mathrm{~m}^{3} / \mathrm{s}$. A tomada d'água é do tipo torre, com altura máxima de 31,5 $\mathrm{m}$ e três entradas de controle. O Maciço de barramento localiza-se a $15 \mathrm{~km}$ da sede Municipal da cidade de Teófilo Otoni.

As equações que regem o escoamento, gradualmente variável em superfícies livres, foram propostas por Saint Venant, em 1871. Essas equações traduzem os princípios físicos da conservação de massa e da conservação da quantidade de movimento. A modelagem matemática da propagação de uma onda de cheia, gerada pela ruptura de uma barragem, requer a utilização das equações de Saint Venant. A partir de uma abordagem unidimensional, as equações podem ser descritas da seguinte forma:

$$
\begin{aligned}
& \frac{\delta h}{\delta t}+u \frac{\delta h}{\delta x}+h \frac{\delta u}{\delta x}=0 \\
& \frac{\delta h}{\delta t}+u \frac{\delta u}{\delta x}+g \frac{\delta h}{\delta x}=g\left(S_{0}-S_{f}\right)
\end{aligned}
$$

Em que :

$\mathrm{t}=$ variável independente relativa ao tempo [s];

$\mathrm{x}=$ variável independente relativa à direção do escoamento [m];

$\mathrm{u}=$ velocidade média do escoamento $[\mathrm{m} / \mathrm{s}]$;

$\mathrm{g}=$ aceleração da gravidade $\left[\mathrm{m} / \mathrm{s}^{2}\right]$;

$\mathrm{h}$ = espessura da lâmina líquida [m];

So = declividade média da calha fluvial ou do fundo

do canal $[\mathrm{m} / \mathrm{m}]$; e

$\mathrm{S} f=$ declividade da linha de energia $[\mathrm{m} / \mathrm{m}]$

Em termos matemáticos, as equações de Saint Venant são constituídas por um sistema de equações diferenciais parciais de primeira ordem, quase linear, do 
tipo hiperbólico. Esses sistemas não possuem soluções analíticas gerais, por isso, recorre-se então a métodos aproximados ou numéricos para sua solução. Diversos métodos numéricos vêm sendo utilizados na atualidade para a solução de problemas de transientes hidráulicos, em substituição aos métodos algébricos e gráficos, que por possuírem menor precisão, não são de utilização recomendada para análise de sistemas maiores devido a elevada complexidade de contorno" (MENDONÇA, 1986) . Entre os diversos métodos aplicados nestes tipos de problemas, podemos destacar o Método das Características, Método das Diferenças Finitas, Método dos Elementos Finitos, Método Espectral e o Método dos Elementos de Contorno.

Os modelos computacionais possuem a vantagem de permitir a análise de sistemas complexos de engenharia hidráulica, com maior precisão e um menor intervalo de tempo. Assim, é possível utilizar um maior número de seções de integração, obtendo, consequentemente, um aumento de precisão no cálculo do transitório. Possuem destaque, os métodos das diferenças finitas, que são os mais frequentemente utilizados. Outro método, também aplicado, é o dos elementos finitos, que se mostram bastante eficientes, principalmente quando a geometria do problema é de natureza complexa. No entanto, o método das características tornou-se popular e extensivamente usado. Para a solução de problemas transientes unidimensionais, este método tem se mostrado, em muitos aspectos, superior aos outros. Segundo Chaudhry (1987), o método apresenta correta simulação da propagação de ondas, é eficiente e de fácil programação. Além disso, as condições de contorno podem ser as mais diversas. Analisando o problema (ruptura de barramento) sob uma ótica de situações fictícias, em termos práticos, onde o fenômeno é visto sob hipóteses simplificadoras, tais como remoção instantânea e total de uma barreira de largura infinita, liberandose o volume de água armazenado em um canal seco, retangular, e sem considerações sobre a resistência do fundo do canal (MASCARENHAS, 1990), consideramos as seguintes soluções propostas apor Ritter:

$$
\begin{aligned}
& h(x, t)=\frac{1}{9 g}\left(2 \sqrt{g h_{0}}-\frac{x}{t}\right)^{2} \\
& v(x, t)=\frac{2}{3}\left(\sqrt{g h_{0}}+\frac{x}{t}\right)^{2}
\end{aligned}
$$

onde: 
$h(x, t), v(x, t)$ são a altura e velocidade de escoamento na seção de abscissa $\mathrm{x}$, no instante t. $\mathrm{e}$

ho a altura inicial de água no reservatório junto a barragem.

Na Figura 3 temos a representação esquemática das equações modelo de Ritter, onde se pode perceber que entre a localização da barragem e o início da modelagem do escoamento permanente, existe um lapso de tempo e distância onde o modelo não consegue prever o comportamento do movimento do fluido. Neste trabalho esta distância foi estimada em aproximadamente 170 metros, assumindo $t=10 \mathrm{~s} e$ $\mathrm{h}=31 \mathrm{~m}$.

Para o estudo da ruptura hipotética da barragem, considerou-se o reservatório em configuração operacional com nível d'água na cota $32 \mathrm{~m}$ (nível máximo normal) e que todo o volume de armazenamento correspondente, de $12,8 \times 10^{6} / \mathrm{m}^{3}$, seria propagado pela calha a jusante. A propagação da onda de ruptura foi realizada com o método das características. As aplicações das metodologias computacionais por meio deste modelo matemático a ele associados.

Figura 3 - Solução de Ritter para remoção total e instantânea de uma parede retangular

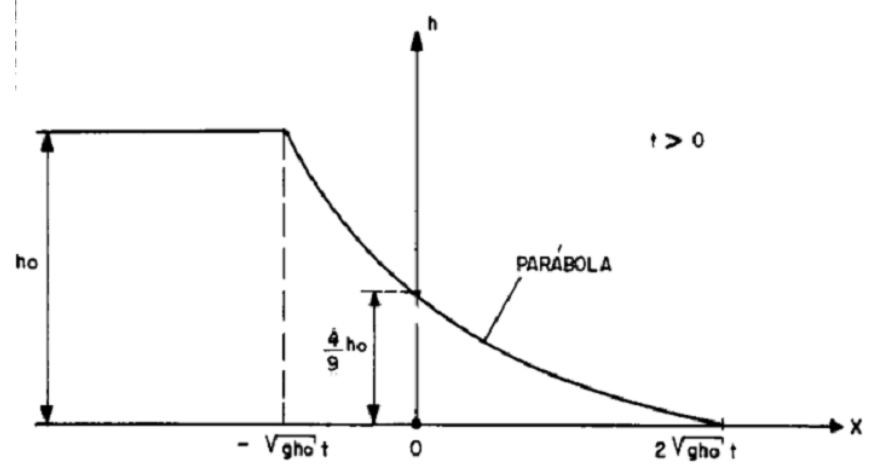

Fonte: Mascarenhas (1990)

\section{RESULTADOS E DISCUSSÕES}

Para o caso de barragem de pequeno e médio porte, nessa aplicação considera-se barragens construídas com alturas entre 15 a 60 metros de altura. Sendo assim, como a altura da barragem do rio Todos os Santos é de 32 metros, ela se encaixa neste intervalo. 
O procedimento que fornece as condições matemáticas no instante da ruptura consiste na determinação de um hidrograma alternativo simplificado de ruptura, a partir do qual valores como o tempo de simulação requerido e condições de fronteira na seção rompida são avaliados. A adoção do hidrograma alternativo simplificado consiste na suposição de variação totalmente linear, a partir do valor máximo de vazão no instante da ruptura até zero, no tempo correspondente ao esvaziamento do reservatório como mostrado na Figura 5. Consequentemente, a área do hidrograma triangular é igual ao volume de água armazenado no reservatório, e, portanto, o tempo estimado para o seu esvaziamento é fornecido pela equação 6. Esse tipo de aproximação, por ser extremamente drástica com respeito ao hidrograma real de ruptura, é utilizado apenas para a quantificação do período de tempo em termos da duração, da propagação numérica e da onda resultante. Dessa forma, a única variável dos modelos matemáticos que sofre uma estimativa, é o tempo total de simulação utilizado, com respeito ao tempo efetivo de esvaziamento associado ao hidrograma real de ruptura. A imprecisão resultante pode ser corrigida pela adoção de um tempo pouco superior ao obtido pela equação 2, como por exemplo, multiplicando-se o valor do tempo de esvaziamento por um coeficiente de correção minuciosamente superior a um.

A vazão máxima de ruptura para o caso em questão, calculada pela equação1, resultou no valor $5739,34 \mathrm{~m}^{3} / \mathrm{s}$, para o qual o hidrograma triangular simplificado de ruptura é mostrado na Figura 4.

Figura 4 - Hidrograma triangular simplificado de ruptura para a barragem de Teófilo Otoni

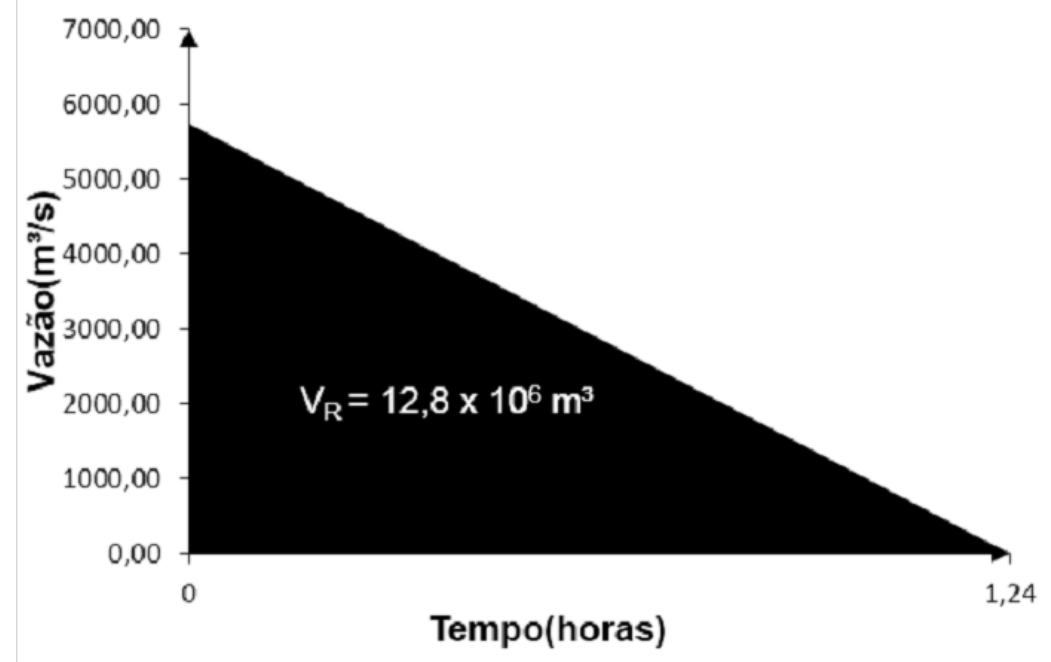


Dessa forma, o tempo estimado de esvaziamento do reservatório, de acordo com a equação 2 é cerca de 4.460,44 segundos (1,24 horas). As alturas máximas de água para cada seção de cálculo da barragem são mostradas na Figura 5, e foram calculados a partir da equação 5 . Pode-se desta forma, prever a planície de inundação. Porém, desconhecendo-a e desconsiderando as irregularidades, o máximo a ser feito é uma estimativa da inundação, utilizando o princípio da conservação de massa. Para estimar a inundação foram feitos cortes transversais na água e calculado a largura do plano fictício produzido pelos mesmos. Levando em consideração que a altura de água mostrada na Figura 5 vai reduzindo quase que linearmente, teremos a largura do corte, a $15 \mathrm{~km}$ da barragem com aproximadamente 79,43 metros.

Com base nos dados encontrados no trabalho, percebemos que a sede municipal de Teófilo Otoni, situada a $15 \mathrm{~km}$ da barragem, seria atingida por um fenômeno de galgamento, cuja altura seria de aproximadamente 3 metros. Consequentemente, pela análise da Figura 5, regiões em que a distância da barragem é menor, serão atingidas por ondas, cujas cristas são maiores, sendo afetadas também pela força e volume da água (FABIANI, 1995; PONCE, 2003).

Figura 5 - Alturas máximas de água a jusante da barragem

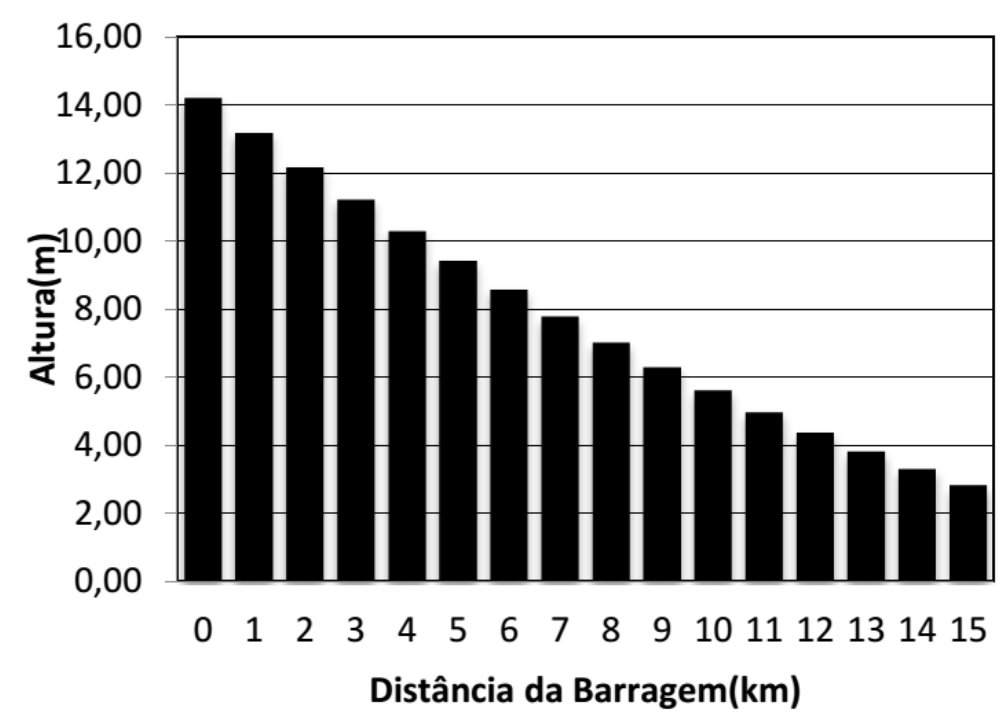

A barragem no rio Todos os Santos é uma alternativa que contribui pra a diminuição de problemas, observados na região, relacionados à falta de água e prevenção contra inundações e enchentes nos períodos chuvosos. Essa obra beneficia a população e resgata seu sentido de segurança. Por esse motivo, o projeto deve ser preciso, avaliando na proposta os riscos factíveis, ocasionados por problemas que podem 
ocorrer na estruturação física da obra ou causas adversas, distantes do controle humano, que venham a colocar em risco a vida da população que se encontra na área da jusante. Dentro da proposta, é imprescindível que haja alternativas seguras de evacuação e proteção da população da área, em caso de emergência.

A análise feita acerca do rompimento hipotético da barragem de Teófilo Otoni, não pode ser aplicada a outras barragens sem a realização de estudos prévios, devido às condições e características adversas diferenciadas que cada tipo de barragem apresenta e que poderiam influenciar nos resultados e estimativas.

\section{CONCLUSÕES}

Os valores encontrados de profundidade máxima para o caso de possível rompimento da barragem de Teófilo Otoni, precisam de um estudo e uma análise mais cautelosa, levando em consideração que foram obtidos por simulações preliminares, podendo haver falha em não considerar algum fator que naquele momento possa influenciar o resultado final. A vazão máxima de ruptura calculada resultou no valor $5739,34 \mathrm{~m}^{3} / \mathrm{s}$, utilizando o hidrograma triangular simplificado de ruptura. O tempo estimado de esvaziamento do reservatório é de aproximadamente 4.460,44 segundos (1,24 horas). Com base nos dados encontrados, percebemos que a sede municipal de Teófilo Otoni, situada a $15 \mathrm{~km}$ da barragem, seria atingida por um fenômeno de galgamento, cuja altura seria de aproximadamente três metros. Observa-se, neste desfecho, que os resultados obtidos no desenvolvimento dessa proposta de estudo, podem ampliar as possibilidades de ações relativas à prevenção de catástrofes, no que tange à construção, manutenção e rompimento involuntário de uma barragem de contenção, e incentivar estratégias emergenciais de apoio, em caso de situações de risco iminente

De qualquer maneira, há fortes indícios de que o vazamento de uma parte do volume de água do reservatório é suficiente para causar elevações no nível de água no rio, prejudicando moradores de regiões próximas ao seu leito. Sendo assim, o rompimento da barragem poderá trazer prejuízos matérias à população e até mesmo de pessoas e animais, tendo em vista uma situação que não há um plano de evacuação e um conhecimento prévio do alagamento da região. Observa-se, neste desfecho, que os resultados obtidos no desenvolvimento dessa proposta de estudo, podem ampliar as possibilidades de ações relativas à prevenção de catástrofes, 
no que tange à construção, conservação e rompimento involuntário de uma barragem de contenção, e incentivar a criação de estratégias emergenciais de apoio, em caso de situações de risco iminente.

\section{REFERÊNCIAS}

BRASIL, L. S. S.; PALMIER, L. R.; NASCIMENTO, N. O; MONTE-MOR, R. C.; VIEIRA, E. e BOTELHO, L. C. Importância do mapeamento de áreas inundáveis para a segurança de barragens: a situação no Brasil. In: CONGRESSO LATINO AMERICANO DE HIDRÁULICA, 22., 2006. [Anais ...] Ciudad Guayana, Venezuela. 2006.

BRASIL, L. S. S.; PALMIER, L. R.; NASCIMENTO, N. O.; BOTELHO, L. C. M.; DINIZ, T. M. F. Modelagem unidimensional de onda de cheia proveniente de ruptura hipotética de barragem-estudo de caso: barragem de Rio das Pedras, Minas Gerais, Brasil. In: XVI CONGRESSO BRASILEIRO DE RECURSOS HÍDRICOS, 16., 2005. [Anais...] .João Pessoa, Paraíba, novembro de 2005.

CHAUDHRY, M. H.; FENEMMA, R. J. Simulation of one-dimensional dam-break flows. Journal of Hidraulic Research, v. 25, n. 1, p.41-51, 1987.

COLUCCI, L. R. Estudo sobre o rompimento do barramento de contenção de cheias de itajubá. EIXO 3A. Especialização em Engenharia de Energia. Universidade Federal de Itajubá, 2011.

FABIANI, A. L. T. Contribuição ao estudo das ondas geradas pela ruptura de barragens. Especialização em Engenharia Hidráulica. Universidade Federal do Paraná, Curitiba. 1995.

MA, Q. L.; WAUCHOPE, R. D.; HOOK, J. E.; JOHNSON, A. W.; TRUMAN, C. C.; DOWLER, C. C.; GASCHO, G. J.; DAVIS, J. G.; SUMNER, H. R.; CHANDLER, L. D. Opus, and PRZM2 model predicted versus measured runoff form a coastal plain loamy sand. Transactions of the ASAE, St. Joseph, v.41, n.1, p.77-88, 1998.

MASCARENHAS, F. C. B. Modelação matemática de ondas provocadas por ruptura de barragens. Especialização em Engenharia Civil) -Universidade Federal do Rio de Janeiro, COPPE/UFRJ. 1990.

MENDONÇA, L. C. de. Estudo dos transientes hidráulicos em uma instalação de bombeamento. Dissertação de Mestrado. EESC/USP, 1986.

PALMIER, L. R. Modelagem Simplificada de Onda de Cheia Proveniente de Ruptura Hipotética de Barragem-estudo de caso: barragem do Aproveitamento Múltiplo Manso, Mato Grosso, Brasil. In: SIMPÓSIO DE RECURSOS HÍDRICOS DO NORTE E CENTRO OESTE, 1., 2007. [Anais...]. Mato Grosso, Brasil. 2007.

PONCE, V. M. Dam-breach flood wave propagation using dimensionless parameters. Journal of Hydraulic Engineering. p.777-782, 2003.

PRUSKI, F. F.; CALIJURI, M. L.; BHERING, E. M.; SILVA, J. M. A. Metodologia baseada no uso de sistemas de informações geográficas para obtenção de equações de chuvas intensas em qualquer localidade do Estado do Paraná. Revista Engenharia na Agricultura, Viçosa, v.5, n.3, p.254-265, 1997. 
RAMOS, C. M.; VISEU, T. Zoneamento territorial: critérios para aplicação dos modelos hidrodinâmicos. SEPREM, Madri, 16 p. 1999. 